\title{
Influence of Landscape Features on Forest Maturity: the Case of a Fragmented Landscape in the Serra do Mar Coastal Forest in Brazil
}

\author{
Simone Rodrigues Freitas ${ }^{1}$, Leonardo de Bem Lignani $^{2}$ \& Diogo Carvalho Cabral ${ }^{3}$
}

\author{
${ }^{1}$ Universidade Federal do ABC - UFABC, Santo André, SP, Brazil \\ ${ }^{2}$ Centro Federal de Educação Tecnológica Celso Suckow da Fonseca - CEFET-RJ, Rio de Janeiro, RJ, Brazil \\ ${ }^{3}$ Department of Geography, University of British Columbia, 1984 West Mall Vancouver, BC V6T 1Z2, Canada
}

\begin{abstract}
This work aims to evaluate which landscape features could influence the maturity of fragments of the Serra do Mar Coastal Forest in the southeastern Brazil. We measured vegetation structure of 11 forest fragments, and used basal area as indicator of forest maturity state. Landscape features were characteristics of forest fragment, including size, shape, altitude, age and spatial evolution (changes such as reduction, expansion or fragmentation); and characteristics of the fragment's surroundings, including distance of the nearest highway, road, urban area and fragment of "continuous" forest, and also type of surrounding human settlement. Linear regression analysis was performed to describe the relationships between forest maturity and landscape features, and AIC was used to select the best model. Spatial evolution of the fragments and distance from the highway, roads and urban areas have better explained forest maturity. Our results could support conservation strategies to identify, locate and protect the more mature forests in tropics.
\end{abstract}

Key words: Atlantic Forest, Basal Area, Human Modified Landscapes, Roads, Tropical Forest.

\section{Introduction}

Deforestation has led to extensive transformation of mature forest into secondary forest. Changes in vegetation structure are basically associated with increased disturbance and decreased plant biomass or basal area (Saiter et al. 2011). Basal area has been shown to be both an indicator of forest maturity state (Brown \& Lugo 1990; Mohandass \& Davidar 2010) and wood extraction (Parrotta et al. 2002).

Landscape features have been related to vegetation characteristics to support diagnostics on maturity or degradation of forest fragments (Teixeira et al. 2009; Pütz et al. 2011; Toivonen et al. 2011). Particularly in human modified landscapes, acessibility and land use may represent relevant landscape features to explain maturity of forest fragments (Gardner et al. 2010; Toivonen et al. 2011). Conservation strategies include preserve or manage tropical forests, even forest fragments located in human modified landscapes, to improve connectivity, increase avaliable habitat and biodiversity (Ribeiro et al. 2009;

\footnotetext{
${ }^{\star}$ Send correspondence to: Simone Rodrigues Freitas Universidade Federal do ABC - UFABC,

Rua Santa Adélia, 166, CEP 09210-170, Santo André, SP, Brasil e-mail: simonerfreitas.ufabc@gmail.com
}

Gardner et al. 2010). Another relevant conservation goal is to keep and increase carbon stocks as a mitigation measure to climate change, most of those stocks are in tropical forests (Saatchi et al. 2011). Thus, it is relevant to identify the more mature forests and using landscape features as indicator could help diagnosis in other regions. This work aims to evaluate which landscape features could influence the maturity of fragments of the Serra do Mar Coastal Forest in the southeastern Brazil. We used basal area to represent forest maturity, and landscape features were characteristics of forest fragment, including size, shape, altitude, age and spatial evolution (changes such as reduction, expansion or fragmentation); as well as characteristics of the fragment's surroundings, including distance of the nearest highway, road, urban area and fragment of "continuous" forest, and also type of surrounding human settlement. We expect that more mature forest may be related to bigger and regularshaped fragments, and those located near to "continuous" forest and far from roads, highways and urban areas. We also expect that how fragment changes in time could affect forest maturity, i.e. more mature forest is expected when fragment increases in size (expansion). 


\section{Material and Methods}

\section{Study area}

We studied 11 forest fragments in Macacu watershed $\left(22^{\circ} 70^{\prime}-22^{\circ} 36^{\prime} \mathrm{S}\right.$ and $\left.43^{\circ} 06^{\prime}-42^{\circ} 55^{\prime} \mathrm{W}\right)$, Rio de Janeiro state, southeastern Brazil (Figure 1). Lowland tropical rain forest covers most of the study area, which is located on the Atlantic hillside of Serra do Mar mountains towards the Guanabara Bay. There are some cities with small populations near fragments: Guapimirim (37,952 inhabitants), Japuíba
$(22,883)$, Cachoeiras de Macacu $(19,183)$, Subaio $(6,477)$ and Sambaetiba (4,940 inhabitants; IBGE's 2000 Census). Most fragments have areas of $\leq 100$ ha and are surrounded by pastures, agricultural fields and human dwellings, generally within small rural properties (Cabral \& Fiszon 2004). The mean size of forest fragments studied is 44.35 ha ( $\pm 26.92 \mathrm{ha}$ ) and the surrounding land use encompass most of variation in the Macacu watershed, representing well the study site. Forests have a close canopy of $35 \mathrm{~m}$ high, with some individuals growing above this layer, and an understory of 5 to $10 \mathrm{~m}$ (Freitas et al. 2005).
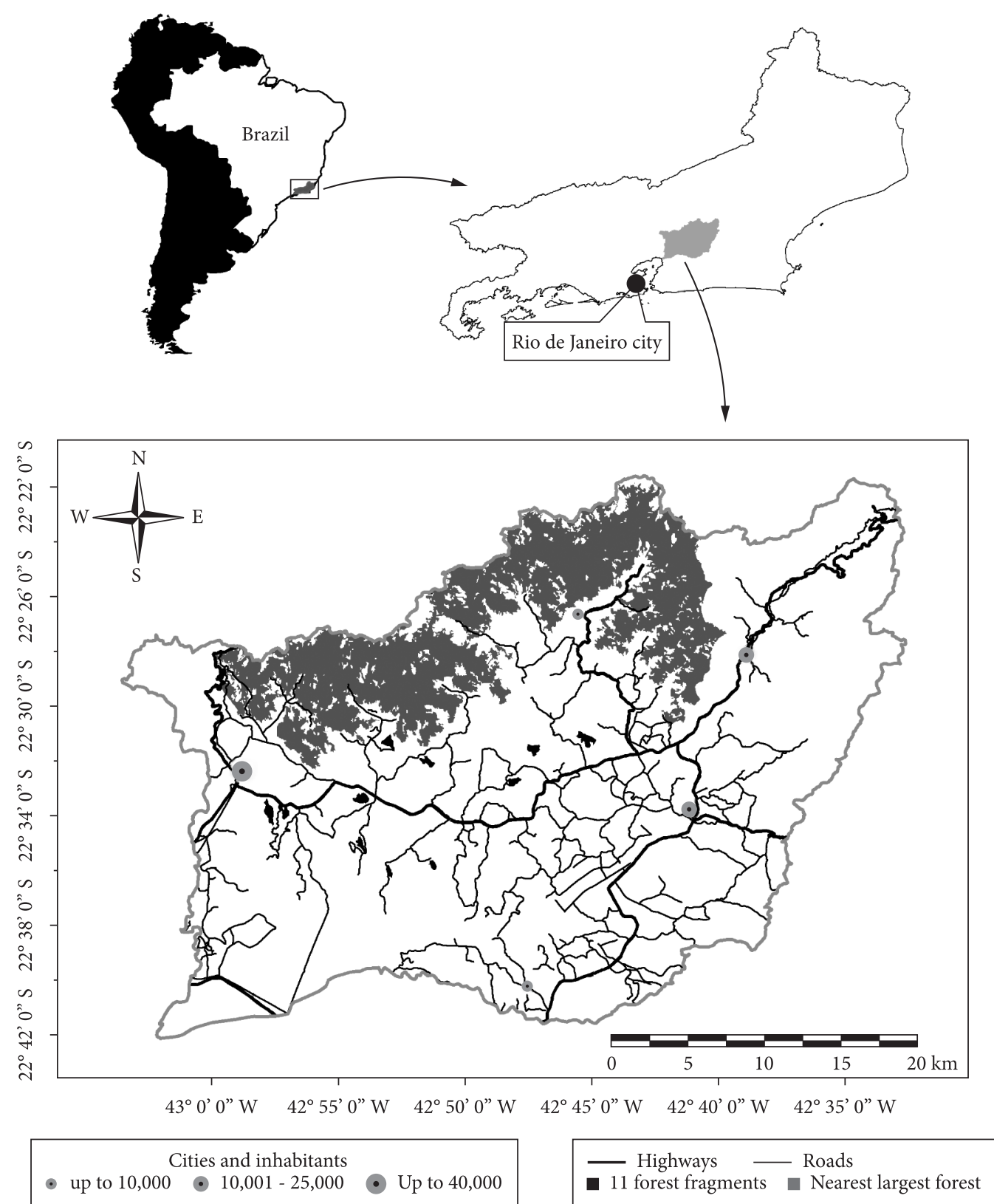

Figure 1. Macacu watershed, in the Rio de Janeiro State, southeastern Brazil. In detail, we show the 11 forest fragments studied (black) and some landscape features as roads, highways, cities and the nearest largest forest (gray). 


\section{Forest maturity}

In the vegetation structure surveys we used two transects crossing each forest fragment (North-South and East-West directions). In each transect, rectangular plots ( 5 by $10 \mathrm{~m}$ ) were allocated $30 \mathrm{~m}$ apart from each other (Freitas et al. 2005). Within each plot, all trees with a diameter at breast height $(\mathrm{DBH})>5 \mathrm{~cm}$ were measured, with $\mathrm{DBH}$ being used in calculations of mean and standard deviation of basal area. We used basal area as indicator of forest maturity state (Brown \& Lugo 1990).

\section{Landscape features}

The landscape features assessed were: 1) fragment size and shape; 2) forest fragment altitude; 3) fragment age; 4) spatial evolution of the forest fragment; 5) type of surrounding human settlement; 6) shortest distance from nearest highway (RJ-122); 7) shortest distance from nearest secondary (rural) road; 8) shortest distance from nearest urban area; and, 9) shortest distance from nearest fragment of "continuous" forest (located in the Serra dos Órgãos). We chose those landscape features to represent characteristics of forest fragments and their surroundings associated to changes on forest structure and richness of tree species due to consequences of forest fragmentation and degradation (Silva et al. 2008; Freitas et al. 2010; Mohandass \& Davidar 2010; Pütz et al. 2011). FRAGSTATS 2.0 (McGarigal \& Marks 1995) was used for calculations of shape index (SHAPE $\geq 1$ ), with high values corresponding to irregular shapes. Distance measurements used ARCGIS 9.2. Land use and land cover map was done based on a classified Landsat 7 ETM+ image from February 28, 2000 (Freitas et al. 2005). Fragment age was estimated by the comparison of orthogonal

Table 1. Classes representing the forest fragment evolution in two time-periods.

\begin{tabular}{ccc}
\hline Classes & \multicolumn{2}{c}{ Time-period } \\
\cline { 2 - 3 } & 1969-1976 & 1976-1996 \\
\hline 1 & expansion & reduction \\
2 & fragmentation & reduction \\
3 & fragmentation & fragmentation \\
4 & no change & fragmentation \\
5 & reduction & expansion \\
\hline
\end{tabular}

black-and-white aerial photographs captured in 1969 (1:60.000, USAF), 1976 (1:40.000, FUNDREM) and 1996 (1:20.000, Fundação CIDE-RJ). Aerial photographs allowed the reconstruction of spatial evolution of the forest fragment between 1969-1976 and 1976-1996, with changes classified into categories: 1) reduction, when fragment decreases in size; 2) expansion, when it increases in size; 3) fragmentation, when fragment is divided in pieces; and 4) no significant alteration, when no change is noticed between two periods (Table 1). Types of surrounding human settlements were classified as (1) one large rural property, (2) several small rural properties, (3) rural properties neighbouring to urban areas (Cabral \& Fiszon 2004).

\section{Analysis}

Generalized linear models were used in order to assess the relationship between basal area and landscape features. Models used Gaussian function as the probability distribution and were selected through Akaike Information Criterion, using a correction for small samples (AICc; Burnham \& Anderson 2002). Dependent variables were vegetation structure measurements (basal area mean and standard deviation), while landscape features were independent variables. Due to limited sample numbers, our models included one or two independent variables. To avoid interpretation of models with uninformative parameters, we include a null model to compete to other regression models, which independent variable was a constant $(y=1)$. Significant differences in the models were detected by the evidence ratio (Burnham \& Anderson 2002). Statistical analyses were performed in R software.

\section{Results}

Mean basal area was better explained by the model that included distance from the nearest highway and distance from the nearest (secondary) road as independent variables (Table 2). Forest fragments that are close to highway RJ-122 and distant from secondary roads were characterized by a higher mean basal area of trees. Another relevant model for mean basal area included only distance from highway as an independent variable (Table 2).

Table 2. Regression models selected by AICc (evidence ratio $\leq 2.0$ ).

\begin{tabular}{ccccc}
\hline Dependent variables & \multicolumn{2}{c}{ Independent variables } & AICc & Evidence ratio \\
\hline Basal area & - highway distance & + road distance & 70.17 & $1.0^{*}$ \\
(mean) & - highway distance & - & 71.28 & 1.7 \\
Basal area & + constant & - & 78.21 & 55.5 \\
(standard deviation) & + forest fragments evolution & - distance of urban area & 78.77 & $1.0^{*}$ \\
& + forest fragments evolution & - highway distance & 79.61 & 1.5 \\
& - highway distance & - & 79.64 & 1.5 \\
& + constant & - & 86.57 & 49.4 \\
\hline
\end{tabular}

where: ${ }^{\star}$ best model selected by AICc; constant $=1$. 
Basal area variation (i.e. standard deviation of basal area) was better explained by forest fragment evolution and distance from an urban area (Table 2). Fragments that expanded or became fragmented between 1976 and 1996 and were close to an urban area showed higher basal area variation, indicating higher forest maturity. Other relevant models that explained basal area variation included distance from a highway as an independent variable (Table 2).

All relevant models (evidence ratio $\leq 2.0$ ) showed better performance than null model, indicating that the selected models included informative variables (Table 2). Size, shape, altitude and age of forest fragment; type of surrounding human settlement and shortest distance from nearest fragment of "continuous" forest were not included in the relevant models.

\section{Discussion}

The landscape features that best explain forest maturity were distance from the highway and roads, distance from urban areas, and the spatial evolution of the fragments. Structurally more developed forest fragments were those closest to the highway and to urban areas, but far from the secondary roads, and showing either a trend of areal expansion or fragmentation in the most recent years.

Generally, both in temperate and tropical regions, the most extensive forested lands are found farther from roads (Hawbaker et al. 2005; Teixeira et al. 2009). In our study, this relationship was found, as expected, between the structural maturity of the forest and the secondary roads. However, the inverse relationship was observed concerning the distance from the highway. What accounts for this difference? The greater maturity of forest fragments near the highway can be explained by the function and history of the latter in the landscape. The highway is mainly a link between urban centers while secondary roads connect the highway with the rural settlements where agricultural and extractive land-uses take place, including the use of the forest fragments themselves (Nagendra et al. 2003). Agriculture represents a more direct pressure on the fragments as a result of felling and burning for the expansion or simple renewal of crops. Moreover, there is the problem of woodcutting, especially for firewood, a practice still common in poor rural households. The removal of wood represents a loss of plant biomass, which reduces the basal area of the forest fragment (Kammesheidt et al. 2002). Fragments closer to secondary roads are more vulnerable to this due to easier access (Nagendra et al. 2003).

Highways and roads therefore have different effects on forest fragments. One can surmise that, before being extended and paved in the 1950s, the highways have had - just as secondary roads have today - a negative effect on vegetation structure. However, 50 years of forest regeneration are enough to produce a structurally mature secondary forest (Kammesheidt et al. 2002).
Roads and highways are evidence of human occupation in a given region. Depending on the historical circumstances, their effects on the landscape can be more persistent than agricultural and extractive land-uses (Freitas et al. 2010). Secondary roads are built for connecting urban and rural places and for transporting food, wood and other products. There is a strong relationship between land-use and the spatial organization of secondary road networks (Hawbaker et al. 2005; Freitas et al. 2010). Likewise, there is a relationship between the land-use dynamics and forest cover dynamics, since deforestation is conducted mainly for the expansion of grazing areas and urban areas in tropics (Teixeira et al. 2009). Roads may have a direct role in deforestation through forest removal during their construction, but the effects do not stop there. The greatest impacts come from the construction and expansion of secondary roads. These roads provide access to forest fragments, making possible the development of agriculture, woodcutting, hunting and other human activities that affect the structure and the function of the forest (Nagendra et al. 2003).

The spatial evolution of the fragment is a relevant factor to be considered when assessing forest maturity state. If a fragment has either expanded or even increase its fragmentation state (e.g. a large patch separated in smaller patches) in the past 20 years, the vegetation structure may appear mature in the present. Due to response delay of the tree community, two different successional pathways can take place: the expansion of the fragment area and the recent fragmentation. In the first case - the expansion of the fragment area - forest regeneration tends to maintain its course: if the situation does not change, the core area of the fragment should increase, reducing the edge effect and increasing forest maturity. In the second case - the recent fragmentation - the course of evolution will probably be the opposite, i.e., tending to forest degradation, if the situation does not change.

The negative correlation between the structural development of forest fragments and their distance from the urban area and from highway could be explained by the less intense use of forest resources by urban dwellers compared to rural dwellers, and near highway compared to secondary roads. Hunting and logging are more common in rural areas and even in small urban centers as Guapimirim. A less intensive use of the forest fragments - especially when it comes to the removal of timber - facilitates their regeneration.

Considering the landscape features that were not enough associated to maturity forest to be included in relevant models, it was unexpected the exclusion of fragment size in those relevant models. Fragment size has been positively related to increase of basal area and tree species richness (Mohandass \& Davidar 2010; Pütz et al. 2011). The mean size of forest fragments studied was 44.35 ha ( $\pm 26.92 \mathrm{ha}$ ), similar to more than $80 \%$ of the fragments found in Brazilian Atlantic Forest with $<50$ ha (Ribeiro et al. 2009). Maybe, the size variation in the study site was not enough to become 
fragment size a relevant landscape feature to explain forest maturity in the present study.

In this study, we have found that structurally developed forest fragments tend to be situated far from those human agents that use their resources most intensively. These agents are rural rather than urban. Urban sprawl generally occurs toward abandoned agricultural lands, but urban land-uses can also spread towards forested land (Teixeira et al. 2009). However, the less intense use of natural resources close to highways can allow forest regeneration and the maintenance of structurally mature fragments. In the case of both urban sprawl and density of secondary roads being high, forest fragments will probably be less structurally developed. Evidently, the degree of structural development also depends on the size of the nearest urban center. In large cities such as Rio de Janeiro, the enormous amount of poor people without access to the labour market makes the probability of occupation of forest fragments or even squatting on forest reserves much higher than in a small peripheral town as Guapimirim. Thus, the results of this study can be generalized to peripheral landscapes, with few paved roads, few and small urban areas, and which are dominated by agro-pastoral activities but where there are remnants of tropical forests. Those landscapes are typical human modified ones located at the fringe of metropolitan areas (suburban sprawl) and in nonmetropolitan areas (rural sprawl) that are near most forest remnants. Suburban and rural sprawl is mainly found in tropical countries and in North America (Radeloff et al. 2005; Teixeira et al. 2009, Toivonen et al. 2011) and should be a issue addressed by nature and landscape conservation. Our results could support conservation strategies to identify, locate and protect the more mature forests in tropics, which have most of carbon stocks and ecosystem services, and also higher degrees of species richness and rates of endemism (Ribeiro et al. 2009; Saatchi et al. 2011).

\section{Acknowledgements}

We thank all staff of Laboratório de Vertebrados of UFRJ, whose work in the field during the PROBIO project. We are grateful to Stephanie Shulhan for reviewing the manuscript.

\section{References}

Brown S \& Lugo AE, 1990. Tropical secondary forests. Journal of Tropical Ecology, 6:1-32. http://dx.doi.org/10.1017/ S0266467400003989

Burnham KP \& Anderson DR, 2002. Model selection and multimodel inference: a pratical information-theoretic approach. New York: Springer.

Cabral DC \& Fiszon JT, 2004. Padrões sócio-espaciais de desflorestamento e suas implicações para a fragmentação florestal: Estudo de caso na Bacia do Rio Macacu, RJ. Scientia Forestalis, 66:13-24.

Freitas SR, Mello MCS \& Cruz CBM, 2005. Relationships between forest structure and vegetation indices in Atlantic
Rainforest. Forest Ecology and Management, 218:353-362. http://dx.doi.org/10.1016/j.foreco.2005.08.036

Freitas SR, Hawbaker TJ \& Metzger JP, 2010. Effects of roads, topography, and land use on forest cover dynamics in the Brazilian Atlantic Forest. Forest Ecology and Management, 259:410-417. http://dx.doi.org/10.1016/j.foreco.2009.10.036

Gardner TA et al., 2010. A multi-region assessment of tropical forest biodiversity in a human-modified world. Biological Conservation, 143:2293-2300. http://dx.doi.org/10.1016/j. biocon.2010.05.017

Hawbaker TJ et al., 2005. Road density and landscape pattern in relation to housing density, land ownership, land cover and soils. Landscape Ecology, 20:609-625. http://dx.doi. org/10.1016/S0378-1127(01)00783-6

Kammesheidt L, Köhler P \& Huth A, 2002. Simulating logging scenarios in secondary forest embedded in a fragmented neotropical landscape. Forest Ecology and Management, 170:89-105. http://dx.doi.org/10.1016/ S0378-1127(01)00783-6

McGarigal K \& Marks BJ, 1995. FRAGSTATS: Spatial pattern analysis program for quantifying landscape structure. Portland: U.S. Department of Agriculture, Forest Service, Pacific Northwest Research Station.

Mohandass D \& Davidar P, 2010. The relationship between area, and vegetation structure and diversity in montane forest (shola) patches in southern India. Plant Ecology \& Diversity, 3: 67-76.

Nagendra H, Southworth J \& Tucker C, 2003. Accessibility as a determinant of landscape transformation in western Honduras: linking pattern and process. Landscape Ecology, 18: 141-158. http://dx.doi.org/10.1023/A:1024430026953

Parrotta JA, Francis JK \& Knowles OH, 2002. Harvesting intensity affects forest structure and composition in an upland Amazonian forest. Forest Ecology and Management, 169:243255. http://dx.doi.org/10.1016/S0378-1127(01)00758-7

Pütz S et al., 2011. Fragmentation drives tropical forest fragments to early successional states: A modelling study for Brazilian Atlantic forests. Ecological Modelling, 222:1986-1997.

Radeloff VC, Hammer RB \& Stewart SI, 2005. Rural and suburban sprawl in the U.S. Midwest from 1940 to 2000 and its relation to forest fragmentation. Conservation Biology, 19:793-805. http://dx.doi.org/10.1111/j.1523-1739.2005.00387.x

Ribeiro MC et al., 2009. The Brazilian Atlantic Forest: How much is left, and how is the remaining forest distributed? Implications for conservation. Biological Conservation, 142:1141-1153. http://dx.doi.org/10.1016/j. biocon.2009.02.021

Saatchi SS et al., 2011. Benchmark map of forest carbon stocks in tropical regions across three continents. Proceedings of National Academy of Sciences, 108:9899-9904. PMid:21628575. http://dx.doi.org/10.1073/pnas.1019576108

Saiter FZ et al., 2011. Tree changes in a mature rainforest with high diversity and endemism on the Brazilian coast. Biodiversity and Conservation, 20:1921-1949. http://dx.doi. org/10.1007/s10531-011-0067-3 
Silva WG et al., 2008. Relief influence on tree species richness in secondary forest fragments of Atlantic Forest, SE, Brazil. Acta Botanica Brasilica, 22:589-598. http://dx.doi. org/10.1590/S0102-33062008000200026

Teixeira AMG et al., 2009. Modeling landscape dynamics in an Atlantic Rainforest region: Implications for conservation.
Forest Ecology and Management, 257:1219-1230. http:// dx.doi.org/10.1016/j.foreco.2008.10.011

Toivonen JM et al., 2011. Accessibility predicts structural variation of Andean Polylepis forests. Biodiversity and Conservation, 20:1789-1802. http://dx.doi.org/10.1007/ s10531-011-0061-9

Received: July 2011

First Decision: August 2011 Accepted: September 2011 